\section{Birth of the Gods}

\section{Fred Hoyle}

The Cosmic Winter. By Victor Clube and Bill Napier. Blackwell: 1990. Pp. 307. £15.95, \$24.95.

THE Solar System possesses an outlying cloud of comets reaching to a distance of perhaps a light year from the Sun - most aphelion distances are probably less than half of that. Otherwise the comet cloud would long ago have been tidally sheared away from the Solar System in an approach to a galactic molecular cloud. But Clube and Napier think that the Solar System has indeed repeatedly lost and then recaptured its cometary cloud. Recapture not being a simple reversal of loss, I would rather think the main cloud to be smaller than assumed.

Comets with near-zero angular momentum possess orbits that plunge deep into the Solar System, where planetary perturbations cause most of them to be ejected. A small fraction evolve with decreasing aphelion distances. Their periodicities shorten greatly, they become more and more degassed, ultimately leaving inert residues thought to be about a kilometre in size. Such residues may be destroyed in planetary encounters or generate more debris through collision with bodies in the asteroidal belt.

This process is enacted in

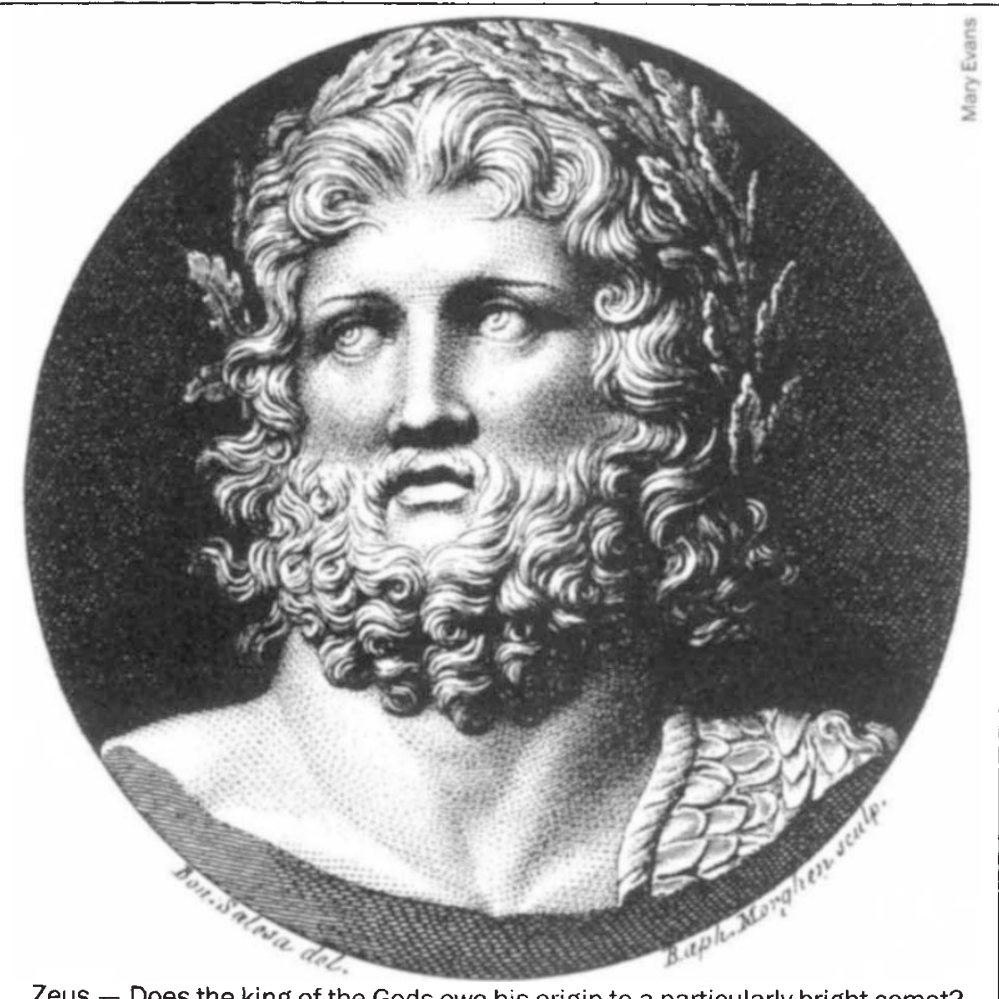

Zeus - Does the king of the Gods owe his origin to a particularly bright comet? orogenic episodes, shifts in plate tectonics and geomagnetic reversals - thereby satisfying Tommy Gold's dictum that in products. A careful analysis of $\mathrm{L}$ and $\mathrm{D}$ alloisoleucine might reveal something useful, but no analysis I have seen is of such a degree of sensitivity.

But spectacular as all this may be, it pales beside the main thrust of the book. First, the authors postulate "giant comets" which in mass are comparable to asteroids, say $10^{21}$ grams, rather than the lower value of $10^{18}-10^{19}$ grams that would be assigned to big comets from observation. Second, they say that such a comet became deflected into an essentially irreversible orbit inside that of Jupiter about 6,000 years ago. Comet Encke and the Taurid meteor streams are regarded as the surviving remnants of the degeneration of such an object. Any surviving large piece of debris, of which Comet Encke may be just one among many, follows a changing orbit that intersects the plane of the Earth's orbit in two nodes. The solar distance of one or other of the nodes may coincide almost precisely with the radius of the Earth's orbit for a duration of about a century, during which interval the Earth will be exposed to debris incident at high speed from without, a challenge to what the authors refer to as the present-day closed-box mentality of the human species. And if there are many such objects with a pair of dangerous nodes, impacts can continue over an extended time interval.

In June 1975 as many one-ton boulders hit the Moon in five days as had hit the Moon in the previous five years. The late June date of this event indicates a few million years, and, given the age of the Solar System, the cometary cloud would have been denuded of comets of small angular momentum if a resupply were not generated by perturbations from outside. The tidal gravitational fields of molecular clouds are the most effective regenerating influence. Such fields depend on the position of the Sun with respect to the galactic disk and spiral arms as well as to the position of individual molecular clouds. Clube and Napier consider this generates periodicities in the supply of comets of small angular momentum, of which they identify a long period of about 230 million years associated with the rotation of the Galaxy, within which there is a shorter period of 15 million years that alternates between effects that are strong and weak.

These periodicities are ultimately reflected in the bombardment of the Earth the advancing of new hypotheses it does not pay to think timidly. On the Cretaceous-Tertiary $(K / T)$ boundary, Clube and Napier are scathing in their comments about the mistakes which have been made by media-sponsored bandwagons that have been set rolling in the past decade, and on the persistent failures of those involved to reference similar work on the subject before their own. Despite their care in these matters there is one important point on which I suspect the authors themselves have been deceived. On page 227 they remark that amino acids found in $\mathrm{K} / \mathrm{T}$ boundary deposits are of nonbiological origin, by which I suppose they mean there are nonbiological amino acids and that the amino acids are racemic. This is a non-sequitur because fossilized biomaterial goes racemic in a time-scale of only 100,000 years, and nonbiological amino acids also appear in the degeneration a connection with the Taurid stream. The Tunguska event occurring on the night of 30 June 1908 was surely also connected with the Taurid stream. Because of their low tensile strength, bolides of stone shatter into many pieces if incident on the Earth's atmosphere, at an altitude of about 10 kilometres, except for bolides of kilometre size which penetrate to ground level and produce craters. The heat released almost instantaneously into the atmosphere is that which would be obtained by burning a lump of coal with a mass about a hundred times greater than the bolide. The mass for the Tunguska event is thought to have been about 30 megatons. The resulting damage on the ground from heat and from the atmospheric blast made human survival unlikely to a distance of about 50 kilometres. Extensive fires must have been started in the surrounding forest. It 
was an event to recall the ancient myth of Phaethon, who being entrusted to take charge of the chariot dragging the Sun across the sky drove too low and set the Earth on fire.

On 25 June AD 1178, five excellent men of Kent saw fire and sparks break out repeatedly from between the horns of a new moon. The body of the moon "writhed and throbbed like a wounded snake" wrote Gervase of Canterbury, a "phenomenon that was repeated a dozen times or more". After the flame had twisted randomly for a while the Moon returned to normal, except that the crescent was now dark instead of bright as it had formerly been. In modern times, satellites have detected a very fresh crater, named (ironically) Giordano Bruno, on the far side of the Moon, which seems to have been produced in an impact of the 100,000 megaton class, sufficient if it had hit the Earth to have devastated at least an entire continent. Clube and Napier do not mention that this event demonstrates the correctness of Gold's view of the dusty nature of the lunar regolith, for it was surely immense clouds of thrown-up dust reflecting sunlight that the men of Kent took to be the fire and the sparks. The basalt flows, so dear to the NASA establishment, would not have produced anything of the sort. It is interesting that an inexpensive but correctly motivated library search would have solved the problem of the nature of the lunar surface, whereas the immensely expensive NASA lunar missions did not - the difference one might say between an open-box mentality and a closedbox one.

Clube and Napier regard a date of about $1000 \mathrm{BC}$ as being crucial in human history. Before $1000 \mathrm{BC}$, and especially in the third millennium $\mathrm{BC}$, bolide impact was far more common than it has been in the period since. In earlier times the skies were ablaze with comets, the many companions of Comet Encke. The emergence of particle jets from comets was interpreted as being similar to the destructive effects of bolide impacts on the Earth. The comets were gods and in firing away with the evaporated jets they were at war with each other. This was the background to ancient myths of the war of the gods. One particular comet lasted in brilliance longer than the others and this became Zeus, king of the gods. On pages 198-199, the authors compare their views on the genesis of ancient myths with the usual explanations, and I must say the usual looks very thin when compared with the brew on offer. Were the bolts of Zeus nothing more than lightning flashes which have only a minuscule probability of killing anyone? Or were they Tunguskalike events about which even hard men would be pressed to maintain their composure. Such events causing forest fires in regions where metallic ores were exposed at the surface could produce reduction to metals. Was this how metal smelting was discovered, in cosmically generated furnaces? Where, I ask myself, did the expression "bolt from the blue" come from? Is there a similar expression in other languages? Splendid stuff! The authors are to be congratulated on having produced a book which seems well calculated to annoy a commendably large number of people.

Sir Fred Hoyle is at 102 Admiral's Walk, West Cliff, Bournemouth BH2 $5 \mathrm{HF}$, UK.

\section{A passage from India}

\section{David Lindley}

Chandra: A Biography of S. Chandrasekhar By K. C. Wali. University of Chicago Press: 1990. Pp. 352. \$29.95, $£ 23.95$.

A NINETEEn-year-old prodigy, travelling by boat from India to England where he is to take up graduate studies in astrophysics, discovers a new, profound and surprising fact about the nature of stars. After a few years at Cambridge, as his reputation is beginning to spread, he makes his discovery known, and, to his great dismay, is attacked - mocked in fact - by a man who was supposed to be his mentor. And although the logic of the young man's argument is irrefutable, the physics of the matter is somewhat abstruse, and the position of his attacker so lofty, that he finds himself largely abandoned.

In this literate and engaging biography K. C. Wali tries, as a novelist would, to make of this episode in the life of Subramanyan Chandrasekhar a key to understanding his subsequent career. The story of Chandra's discovery - that stars above a certain critical mass could not settle down into quiet old age as white dwarfs, but would collapse further into some then inscrutable new state of matter - and of how Sir Arthur Eddington disparaged it not for reasons of physics but because he could not bring himself to believe that nature would allow such a catastrophe, is part of the folklore of astrophysics. Had Eddington, a great expert on relativity, not thrown his weight against the idea, black holes might have been recognized as an astrophysical reality twenty years earlier. But Chandra, though he never doubted his own rightness, chose to disengage from any bitter public dispute with Eddington, and embarked on no lifelong vendetta.

Instead, he moved in 1937 to the United States, first to Yerkes Observatory in Wisconsin and then to the University of
Chicago, where, for half a century, he has cultivated what might be called the high style of research in mathematical physics. He immerses himself in the study of some seemingly remote subject and, after some years of intellectual labour, delivers an encyclopaedic monograph: Radiative transfer; Ellipsoidal figures of equilibrium; The mathematical theory of black holes.

It may be, as Wali suggests, that Chandra's decision to avoid the frenzied and disputatious frontiers of science, finding his satisfaction instead in the full comprehension of each complex problem that he tackles, was a reaction to his fierce encounter with Eddington. But the habit of self-reliance seems to have been instilled at an early age. In British India, when Chandra was growing up, the best schools were reserved for children of the British and of local princes; Chandra was educated mostly at home, by a learned but stern father and then by private tutors. Even then, he supplied his own discipline, working on his exercises in mathematics beyond his father's requirements.

And later, when Chandra's reputation was established in Europe and the United States, he resisted efforts to draw him back to any science position in India, principally, it seems, because he wished to stay aloof from the incessant squabbling that afflicted Indian science. In the middle decades of this century there were a number of distinguished Indian scientists, including $\mathrm{H}$. Bhabha, $\mathrm{S}$. N. Bose, M. N. Saha and Chandra's uncle, the Nobel laureate C. V. Raman, most of whom seemed to spend a good deal of their time scheming against the others. Although Chandra at one time likened the quality of life in the United States to distilled water, his position in Chicago afforded him the calm to indulge his intellectual tastes.

Wali writes persuasively of the difficulties encountered by an Indian trying to make a career in western science. Chandra had to endure patronizing British officials who hinted that he would soon find himself out of his depth, and scientists too respectful of Eddington and their own caste system to come forthrightly to his defence. And when he had made his name in the United States he was sniped at by scientists and bureaucrats back in India for his refusal to return. Those who know Chandra through his scientific reputation will find here many clues to an apparently distant character. His pleasantly dictatorial stewardship of the Astrophysical Journal, which he edited for many years, shows a man who will do no favours and waive no rules. $\mathrm{He}$ offended many astronomers, who had until then regarded the journal as an outlet for whatever they deemed suitable, but he made the Astrophysical Journal into a serious publication. And if it seems 